Dialectologia 25 (2020), 219-236.

ISSN: 2013-2247

Received 31 August 2018.

Accepted 22 November 2018.

\title{
TEOCHEW DIALECT: A CASE OF LANGUAGE SHIFT
}

\author{
Tan Kim HuA \& Woo Mei FoONG \\ Universiti Kebangsaan Malaysia * \\ kimmy@ukm.edu.my / wimifung@gmail.com
}

\begin{abstract}
This paper looks into the language shift of Teochew, a dialect of the minority Chinese community in Klang, Malaysia. The aim of this research is to rationalise the language shift of Teochew to other Chinese languages, such as Mandarin. Two theoretical frameworks guided the methodology; that is, a) the linguistic variation framework, and b) the "acts of identity" framework. A combination of both of these frameworks enabled the scrutiny of external and the internal forces that caused the linguistics variation, and the identification of the attitudes of the younger generation of Teochew speakers towards Teochew. Findings indicated that the younger generation of Teochew speakers in Klang is indeed participating in the process of language shift from Teochew to Mandarin, and they displayed more negative attitudes than positive ones towards Teochew. Although they do not look highly upon their native language, they still think that knowing their native language is important. External factors, such as the demographic factors and the mass media too contributed to the rate of the language shift.
\end{abstract}

\section{Keywords}

Teochew, language shift, identity, dialect

\section{EL DIALECTO TEOCHEW: UN CASO DE CAMBIO LINGÜÍSTICO}

\section{Resumen}

Este artículo analiza el cambio lingüístico en teochew, un dialecto de la comunidad china minoritaria en Klang, Malasia. El objetivo de esta investigación es explicar el cambio lingüístico en teochew junto con otros idiomas chinos, como el mandarín. Dos marcos teóricos han guiado la metodología: a) el marco de variación lingüística, y b) el marco de "actos de identidad". Una combinación de ambos marcos ha permitido

\footnotetext{
* Faculty of Social Sciences and Humanities, Universiti Kebangsaan Malaysia, 43600 Bangi, Selangor.
} 
el escrutinio de las fuerzas externas e internas que provocan la variación lingüística y la identificación de las actitudes de la generación más joven de hablantes de teochew hacia su propia lengua. Los resultados indican que la generación más joven de hablantes de teochew en Klang participa en el proceso de cambio lingüístico de teochew a mandarín, y mostró más actitudes negativas que positivas hacia el teochew. Sin embargo, aunque no valoran mucho su lengua materna, todavía piensan que conocerla es importante. Factores externos, como factores demográficos y medios de comunicación también han contribuido al cambio lingüístico.

\section{Palabras clave}

Teochew, cambio lingüístico, identidad, dialecto

\section{Background of Study}

Language is an important symbol of ethnic identity. The selection and use of language are assumed to be closely related to maintenance of identity. However, the younger generation feels the other way, and has a negative attitude towards their native tongue, especially respondents that are involved in this study. Findings show that $12 \%$ of the respondents are in the opinion that the Teochew dialect has no added advantage or any importance.

For some immigrant and minority languages in the world, language shift and even language death appear to be the outcome of contact with the more powerful local languages. This research is significant for the Chinese communities in the society. The Chinese communities need to be aware that language, culture, and identity are very much related to one another. Therefore, language is an important symbol of ethnic identity. The older generation of Teochew speakers should realise the importance of propagating the language to the younger generation, so that Teochew will not be a "moribund" language.

Language is not rigid and will constantly change, develop and grow to suit the volatile environment. Thus, every member of the community undergoes these deep social and language changes. The most common scenario is when two different languages come into contact. There is bound to be conflict, and the result is that one language will 
supplant the other. It is usually the languages of the minority groups that are being supplanted by the language of the majority or dominant groups.

Kloss (1984: 65) had identified three types of language death:

1. Language death without language shift (the speech community dies out)

2. Language death because of language shift (the speech community does not exist within a 'compact speech area', or the language succumbs to 'the intrinsic hostility modern civilisation')

3. Nominal language death through a metamorphosis (e.g. a language is downgraded to dialect status when the speech community stops writing it and begins to use another closely related variety or the language undergoes 'partition').

According to Krauss (1992: 2), as many as half of the estimated 6000 languages spoken on earth are "moribund", which means languages that are no longer being spoken by the native speakers. Many have considered that the possession of a given language is essential to the maintenance of group identity. Therefore, language has increasingly been investigated as an integral part of human social life, within areas of linguistics, sociology and psychology.

Chinese language comprises many dialects and they are not homogenous. For this reason, they are mutually unintelligible and they are referred as languages (Chinese Language Encyclopedia Articles: Encyclopedia Deluxe: World English Edition Encarta CDROM 1999). Thus, Teochew in this research paper is known as a language by itself. Yet traditionally, and according to their speakers, they are dialects. This perception is partly due to the fact that all the Chinese language employed a common written form.

Although the main Chinese language in Klang, Selangor, is Hokkien, there is a reason to believe that other Chinese languages, such as Teochew is still in use by a small group of the community. But Teochew is only used in certain domains, such as to communicate with family members and other Teochew speakers. Therefore, there is a good reason to believe that Teochew might be dying. This is not because of the decreasing number of Teochew people in Klang, but more importantly is the decreasing number of Teochew speakers. It is believed that the Teochew speakers are shifting from Teochew to other languages, such as Mandarin, Hokkien and Cantonese. This is due to the influence of the 
internal forces such as the attitudes of the speakers, and the external forces such as the mass media and the demographic factors. In addition, this language shift might lead to the language death of Teochew. Furthermore, there is a reason to believe that it is the younger generation that contributed to the decaying of Teochew.

The main aim of this research is to find out the reasons behind the decline of Teochew in Klang town. This research also aims to identify the different social or nonlinguistic factors that influence the speakers to participate in the process of language shift. Its specific objectives are:

1. To describe the Teochew speakers' attitudes, especially the younger generation's attitudes towards Teochew.

2. To provide a realistic view of Teochew in Klang; that is, whether this language is decaying or dying.

3. To describe both the internal and external forces that influenced language shift.

There are two frameworks in this research; the linguistics variation and the "acts of identity" framework. These two frameworks were combined in order to conduct this research. Social identity theory is a theory where an individual's identity revolves around the social group they are associated with (McLeod 2008). Gal (1979: 3) claimed that changes in language choices derive from changes in how speakers wish to present themselves in interaction.

The linguistic variation framework involves two languages: one is the local dialect, and the other is the standard one. This framework is presented in a different context, and it is not just a matter of pronunciation differences, or vocabulary choices, or grammatical variation. According to Holmes (1994: 8), this framework is made popular by two sociolinguists in the late 1960s. They used this framework to conduct research in a village in northern Norway, where all the villagers know and use two distinct kinds of Norwegian. One is the local dialect called Ranamal, and the other is the standard dialect or standard Norwegian called Bokmal. Through this framework they tried to scrutinise the reasons why the speakers practiced language shift, from Ranamal to Bokmal.

This method is supported by Blount \& Sanches (1977: 23). They stated that variation in performance must be included in any theory of a language code. Without such an inclusion, variation is seen as neither a regular phenomenon nor an on-going process, 
which can be observed and explained. William Labov and others have demonstrated clearly that the linguistic variation that is caused by the external and the internal forces are closely interrelated in the process of language change.

Furthermore, the "acts of identity" framework will enable the researcher to identify the attitudes of the younger generation towards their native language. A framework by Le Page \& Tobouret-Keller (1985: 14) is an access to the process of emergence and disintegration of identities and the resulting language shift or language maintenance.

The combination of both frameworks will enable the researcher: a) to scrutinise the external and the internal forces that caused the linguistic variations and b) to identify the attitudes of the younger generation of Teochew speakers towards Teochew.

\section{Language Shift}

In nearly every part of the world, languages are becoming extinct, especially indigenous languages. According to Brenzinger (1991: 10), 90 percent of the existing languages today are likely to die or become a seriously embattled within the next century.

The process of language shift has received a lot of attention among sociolinguistics since the mid-1960s (Mohamad Subakir 1998: 28). Most of the researchers relate the internal and the external forces to the processes of language shift. For example, Dorian (1981: 28) showed that the concept of ethnicity is important in language shift. This is because it influenced the internal forces - that is, the attitude of the speakers. Thus, as the language seen as an important symbol of ethnicity, it is generally maintained longer. Besides this, Dorian (1981) and Gal (1979) too revealed many of the social determinants involved in language shifts. These social determinants are the external forces that influenced the linguistic variation of a certain speech community.

Mohamad Subakir (1998) conducted research on the language shift of Javanese to Malay in Sungai Lang. The Javanese in Sungai Lang, are considered the minority among the Malay community. In his research, he used the linguistic variation framework and the "acts of identity" framework to analyse the reason for the language shift. Through these 
frameworks, he was able to identify the attitudes of the Javanese towards their native language and those external forces such as the geographic areas, social status, occupation and many more that caused linguistic variation.

Mohamad Subakir's main concern is the attitudes of the younger generation towards Javanese. This is because the attitudes of the speakers will determine whether the speakers will maintain their native language or participate in language shift. Hence, his findings on the attitudes of the younger generation will be used as a guideline for this research of Teochew in Klang. In his research, he identified three different codes that the villagers used in their daily lives: Malay, Javanese and Javanised Malay (which is mainly used by older villagers or those who had learned Malay only later in their lives, usually through formal instruction in school).

In his findings, he found out that the villagers have a positive view towards Malay language, in contrast to Javanese and Javanised Malay. There are four categories of villagers who favour Malay over their native language: (most of the) female villagers, the younger villagers, those who had better educational backgrounds and those who aspired to be upwardly mobile socio-economically.

Basically, he is more interested in looking into the attitudes of the villagers towards their native language. Although attitudes are the internal forces that caused language shift or language maintenance, it too is an entity that is influenced by the external forces. This is pointed out by Potowski (2013) as she mentioned how despite the positive attitude towards Spanish in the United States, the speakers would shift to English by the third generation hence proving that positive attitudes toward a language in itself does not guarantee language maintenance.

In Subakir's analysis, he found out that the number of younger generation who uses Javanese is decreasing. Moreover, there are very few of the younger informants that actually admitted outright that they spoke Javanese in or outside of the family. Furthermore, the use of Javanese is limited to only very few villagers who for specific reasons are still very attached to Javanese, and they use Javanese in limited domains such as with family members and in the neighbourhood.

As a whole, the Javanese themselves tend to view Javanese as a handicap to their children's education and socio-economic advancement. These findings of the younger 
generations' attitudes are adapted to the research of Teochew in Klang, where its focus is also the younger generation.

Ding (2016) found that parents who choose to not speak the heritage language would later influence their children's language use and the children's proficiency in the heritage language as well. Her studies also confirm the trend of reducing the use of heritage language and adapting Mandarin as a primary language among the younger generations in Malaysia as they prefer to use Mandarin even in the family domain.

The external factor that Mohamad Subakir (1998) looked into is occupation or socio-economic standing, which influenced the attitudes of the speakers. In general, villagers who are white-collar workers and factory workers used Malay more than labourers or farmers. This is because Malay language is associated with modernisation, and at the same time associated Javanese with traditional or backward values. This view is not only shared by the younger generation, but by most Javanese. Hence, when Javanese came into contact with the factor of socio-economic status, most Javanese speakers will associate Javanese with a negative attitude. Thus, this negative attitude towards Javanese contributed to the language shift.

Mohamad Subakir's findings are important in the research on the Teochew language in Klang. This is because this research too aimed to describe and identify the younger generation's attitudes towards Teochew language. Mohamad Subakir's research provided a useful guideline for the researcher to analyse the decaying Teochew language in Klang.

Beside Mohamad Subakir's research, there is also the research done by Terra (1983: 126-146) titled The Effects of Language Planning on a Penang Hokkien Kampung: People Separated by a Blade of Grass Could Not Understand Each Other. The thrust of this research is however, on language planning of the national language; that is, Bahasa Melayu, on a targeted population. This language planning leads to language shift, where certain speakers of Hokkien in the targeted community practised language shift from Hokkien to Bahasa Melayu.

The findings of the research showed that the speakers shifted their native language to the national language because of the socio-economic impact of the language planned. 
This is because the planned language determined the speakers' social class. Hence, the socio-economic aspect is the external factor that determined the speakers' attitudes toward their native language. This is supported by by Dobrin (2014) where speakers express regret about the language loss but language shift is inevitable as the sentiment coexists with the desire for development.

\section{Research Framework}

The descriptive method is used to conduct this research, where the data were collected using questionnaires. Besides this, data were also collected through the observation method. This is achieved by attending a meeting at the Teochew Association. Apart from that, data were also collected through an interview with the President of the Teochew Association. The data collected from the observation and the interview method served to reinforce the findings of the questionnaires. This research used the abstract descriptive method as it enables the researcher to describe the behaviour and attitudes of the Teochew community especially the younger generation's attitudes toward their native language. This method too enables the researcher to find out the reasons behind this language shift which finally lead to language death. Furthermore, this method will also highlight the existence and the extent of this language death problem.

The concrete descriptive method is not used in this research because most of the members are from the middle or working class. Therefore, the researcher need not categorise the respondents into their respective professions. Moreover, because the respondents' actions or attitudes toward their native language are influenced by other more powerful factors, namely the external factors such as the mass media and the demographic factors. The population of this research is made up of the members of the Teo Chew Poi Yip Association Klang and Coast Districts (TAKCD). At the present stage, there are 756 members in the association and the members are divided into two groups; that is those who are a) above 45 and those b) below 45 . About $60 \%$ of its members fall under the first group, while the rest fall under the second group. The second group, which 
are also known as the 'Youth Movement' of the association, its members' age ranged from 15 to 45 years old and they are the main focus of this research.

The researcher further narrows down the participants to those who are below 30 years old and there are the ones that are considered as the younger generation of Teochews in this research. There are 50 respondents in this research.

There are a few variables that were controlled in this research: a) the participants must be under 30 years old, b) the respondents must be from the 'Youth Movement' of the TAKCD and c) either one or both of the respondent's parents must be a Teochew originate.

The questionnaire contained four distinct type of question content: behaviour, beliefs, attitudes and attributes (Dillman 1978: 80). The questions in the questionnaire are both in the open-ended and closed-ended format. The questionnaire is bilingual, in English and Mandarin because some of the respondents might not be fluent in English and might be more comfortable using Mandarin.

Besides the external forces, the parents also influenced the characteristic of the respondents. According to Holmes (1994), in her discussion of bilingual parents, pointed out that parents initially decide the children's language. The characteristics of the respondents such as their knowledge about Teochew language, their mother tongue, their proficiency in using Teochew language and so on, are controlled by their parents.

This description about how the parents influenced the children or in what way the parents can influence or control the children is important because it will shape the attitudes and behaviour of speakers toward their native language. This objective can be seen in the Appendix: Question 2-7.

Question 2 and 3 enabled the researcher to find out whether the respondents' parents are Teochew originate or not, and what languages they used to communicate with their children. Question 4 asks for the respondents' mother tongue while Question 5 and 7 enabled the researcher to identify the respondents' proficiency in Teochew. Question 6 enabled the researcher to discover the domains of which Teochew is used.

The positive attitudes of the respondents show that they will continue using the language and will encourage and transmit it to the next generation. Furthermore, the 
positive attitudes support efforts to use the minority language in a variety of domains, and this helps the speakers to resist the pressure from the majority group to switch to their language.

Conversely, the negative attitudes of the respondents that can be traced in the questionnaire shows that they have the tendency to stop using the language because they respond negatively toward their native language. Thus, leading to language shift from Teochew to Mandarin, which leads to language death of Teochew.

The research on language attitude was introduced in 1960 by Lambert, Hodgson, Gardner \& Fillenbaum (1960: 30) when they introduce the "matched-guise" technique as a means of assessing language attitudes.

The external factors in this research consist of the demographic and the mass media factors. The external factors are also relevant in accounting for the speed of language shift. In the demographic factors, Klang is known as a place where most of the Chinese are Hokkiens and the Teochews, and are considered the minority. Furthermore, most of the Chinese use Mandarin, the standard Chinese language to communicate. Thus, this situation or environment does not permit the speakers of Teochew to use their language widely. Moreover, Klang is a big city and the Klangites are influenced by the pull of outside forces. Thus, it is hard for the Teochews to use their indigenous language on a regular basis. Questions that consider both of these factors can be seen in the Appendix: Question 9, 10, 11, and 19.

Besides using the questionnaire, an observation was carried out when the researcher attended a short meeting on 23 December 1999 conducted by the President of the 'Youth Movement' of the association. The main reason the researcher attended this meeting is to distribute the questionnaire to the selected group of respondents. Hence, it was an opportunity to conduct an observation in which the results will further validate the findings.

A short interview with the President of TAKCD was conducted on January 5, 2000. Below are the questions that were asked:

a. What is/are your opinion(s) about the survival of Teochew language in Klang?

b. What do you think is/are the attitudes of the younger generation towards Teochew? 
c. Why is Teochew not popular among the younger generation?

d. Why is Mandarin used instead of Teochew among the younger generation, especially in a meeting?

The researcher visited TAKCD to find out the date that the 'Youth Movement' will have meeting with all of their members and to get permission to attend the meeting. $A$ meeting was held on 28 December 1999. In this meeting the researcher collected data through observation and distributed 60 questionnaires to the respondents who are aged below 30 years old. However, only 50 questionnaires were used for data analysis.

The completed questionnaires were collected from the secretary of the association on January 5, 2000 and a short interview with the President of TAKCD was conducted on the same day. 54 questionnaires were collected and 4 questionnaires were taken out randomly to be kept as back up samples in case of "spoiled" questionnaires. All questionnaires were numbered for easy reference and analysis.

Descriptive statistics is used to analyse collected data. This method will enable the researcher to summarise the responses of respondents and results were tabulated.

\section{Language Shift in Teochew Community}

Findings show that the younger generation of Teochew speakers shift language as $52 \%$ of the respondents placed Mandarin as their "number one" language followed by English (refer to Table 1). It was found from the interview with the President of TAKCD that the language shift to Mandarin is due to it being the formal medium of instruction in schools. It was also found that the Teochew dialect is often used in interaction between family members especially those involving the older generations: the grandparents. 


\begin{tabular}{|c|c|c|c|c|c|c|}
\hline \multirow{2}{*}{ Rank } & \multicolumn{6}{|c|}{ Type of Languages } \\
\cline { 2 - 7 } & Teochew & Mandarin & Hokkien & English & Malay & Others \\
\hline 1 & $9(18 \%)$ & $26(52 \%)$ & $3(6 \%)$ & $12(24 \%)$ & - & - \\
\hline 2 & $5(10 \%)$ & $13(26 \%)$ & $4(8 \%)$ & $27(54 \%)$ & - & $1(2 \%)$ \\
\hline 3 & $3(6 \%)$ & $10(20 \%)$ & $24(48 \%)$ & $9(18 \%)$ & $3(6 \%)$ & $1(2 \%)$ \\
\hline 4 & $14(28 \%)$ & $1(2 \%)$ & $19(38 \%)$ & $2(4 \%)$ & $11(22 \%)$ & $3(6 \%)$ \\
\hline 5 & $14(28 \%)$ & - & - & - & $19(38 \%)$ & $17(34 \%)$ \\
\hline 6 & $5(10 \%)$ & - & - & - & $17(34 \%)$ & $28(56 \%)$ \\
\hline
\end{tabular}

Table 1. The Ranking of Languages

Table 2 shows the domain use of the Teochew dialect in the community where the highest percentage of use is in interaction with family members which are the grandparents (43\%), followed by parents and siblings (32\%) and relatives (20\%). Interaction with friends had the lowest percentage which is $6 \%$.

This process will eventually lead to language death if there is no realisation of the importance of one's native language. They participate in the language shift process because they cannot identify themselves as Teochews. Moreover, they feel that Mandarin is more promising than Teochew.

\begin{tabular}{|l|c|c|}
\hline \multicolumn{1}{|c|}{ Domains } & Number & Percentage (\%) \\
\hline Grandparents & 23 & 43 \\
\hline Parents and siblings & 17 & 32 \\
\hline Relatives & 11 & 6 \\
\hline Friends & 3 & 20 \\
\hline
\end{tabular}

Table 2. The Domains of Use of Teochew 


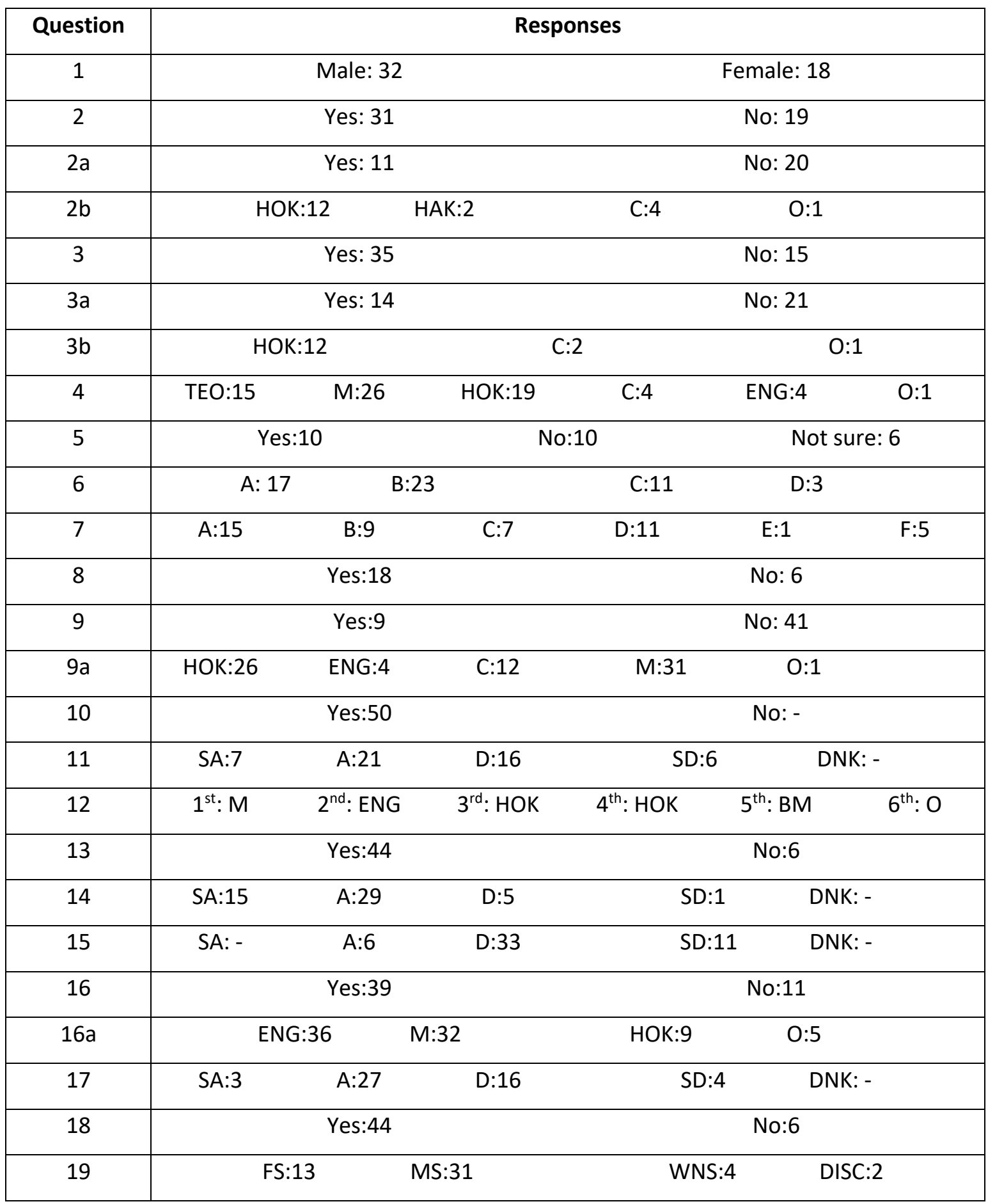

Table 3. Overall Results of Closed-Ended Questions

Legend

$\begin{array}{llll}\text { HOK } & \text { Hokkien } & \text { SA } & \text { Strongly agree } \\ \text { HAK } & \text { Hakka } & \text { A } & \text { Agree }\end{array}$




$\begin{array}{llll}\text { M } & \text { Mandarin } & \text { D } & \text { Disagree } \\ \text { TEO } & \text { Teochew } & \text { SD } & \text { Strongly disagree } \\ \text { C } & \text { Cantonese } & \text { DNK } & \text { Do Not Know } \\ \text { ENG } & \text { English } & \text { FS } & \text { Fully support } \\ \text { BM } & \text { Bahasa Melayu } & \text { MS } & \text { Might support } \\ \text { O } & \text { Other than Chinese } & \text { DISC } & \text { Discourage } \\ & \text { language } & \text { WNS } & \text { Will not support }\end{array}$

In regard to the speakers' attitudes, $80 \%$ of the respondents (refer to Table 3 for Question 6, 8, 13, 14, 17, 18 and 19) showed positive attitude toward the Teochew dialect and think it is important to know their native language:

a. so that Teochew will not become the language of the minority

b. so that Teochew will become a common language in Klang

c. so that as person understand more languages, he/she will gain advantage over those who don't

d. there will be more Teochew speakers

e. because it is their native language

f. in order to gain more knowledge by knowing more languages, especially their own native language

g. for solidarity

The rest of the respondents showed a negative attitude toward the Teochew dialect and they disagreed that the dialect has any added advantage. Below are the respondents' opinions:

a. the dialect does not contribute to the development of the society

b. it is not the lingua franca of the Chinese community

c. as it is the language of the minority, it has a very limited domain

d. Mandarin is far more important than Teochew

e. knowing Teochew is a handicap 
f. knowing the dialect will not enable someone to be accepted by the dominant society

g. Teochew is not an important language, it is therefore unnecessary to acquire proficiency in the language

The internal and external forces influence the decline of the Teochew speakers in Klang. The internal forces include the attitudes of the speakers, and the external forces are the demographic factor, the mass media, and the parents. Both external and internal forces are part of the research framework.

External force such as demographic factors contributes to the acceleration of language shift. It was found that Klang is one of the places where the majority of its community is Icoated: 89,064 people or $37 \%$ is of Chinese ethnicity, followed by Malays at 84,206 people or $35 \%$ of its community. Based on local authorities' survey, it was also found that the Hokkien and Teochew are only a minority. This prevents or dampens the wide usage of the Teochew dialect. The Teochew association itself does not use the dialect during meetings with its members and instead, Mandarin is used for communication. This shows that the environment itself is not moving towards upholding the language.

Additionally, the mass media also influences and promotes the use of a language. For example, most programs curated for the Chinese community are mostly in Mandarin or Cantonese. The audience are naturalised and become so used to the language that it naturally becomes the language of everyday use. The Teochew dialect therefore only exists as a dialect that is rarely used and more of its speaker's language shift from Teochew to Mandarin or Cantonese.

The negative attitude of young generation toward the Teochew dialect is also influenced by the parent. Most parents realise the importance of the Teochew dialect although they doubt that they have the ability to pass the language to their children. This is also one of the obvious contributions to language loss. 


\begin{tabular}{|l|c|c|c|}
\hline \multicolumn{1}{|c|}{ Parents } & \multicolumn{2}{c|}{ Teochew } & Non-Teochew \\
\hline Mother & \multicolumn{2}{|c|}{31} & 19 \\
\hline Speaks Teochew to you? & Yes:11(35\%) & No:20(65\%) & 15 \\
\hline Father & \multicolumn{2}{|c|}{35} & - \\
\hline Speaks Teochew to you? & Yes:14(40\%) & NO:21(60\%) & - \\
\hline
\end{tabular}

Table 4. Use of Teochew between Parents and Respondents

Table 4 shows the percentages of Teochew used in the interaction between parents and their children i.e. the respondents. Findings show that $65 \%$ of mothers of Teochew originate do not use Teochew when interacting with the respondent and the same goes for $60 \%$ of fathers of Teochew originate.

However, the remaining $35 \%$ of Teochew mothers and $40 \%$ Teochew fathers use the dialect when interacting with their children, which could indicate that they realise the advantage of knowing the mother tongue. This is supported by findings from the questionnaire discussed earlier.

It was also found that some of the respondents are ambivalent toward the Teochew dialect, as despite acknowledging Mandarin as a prestigious language, they still want to learn the dialect. This might be due to them identifying themselves as a Teochew and wanting to maintain the dying dialect.

\section{Conclusion}

The decline of languages often has a predominance of older speakers. In this study, it was found that majority of the parents did not pass on the Teochew dialect to their children and most of the respondents themselves do not identify themselves as being Teochew. The lack of transmission is the main contributor of language loss. Through observation, the Teochew association too does not provide a strong group identity to its community as they prefer using Mandarin over the dialect itself. 


\section{References}

BLOUNT, B.G. \& M. SANCHES (ed.) (1977) Sociocultural Dimensions of Language Change, New York: Academic Press.

BreNZINGER, M. (ed.) (1992) Language Death: Factual and Theoretical Explorations with Special Reference to East Africa, Berlin: Mouton de Gruyter.

ClYNE, M. (1982) Multilingual Australia, Melbourne: River Sein Publications.

DILLMAN, D.A. (1978) Mail and telephone surveys: the total design method, New York: Wiley.

DING, S.L. (2016) "Role of Parents in Heritage Language Maintenance in Malaysia", Malaysian Journal of Chinese Studies, 5(1), 15-27.

DoBRIN, L. M. (2014) “Language Shift in An 'Importing Culture': The Cultural Logic of The Arapesh Roads", in K. Austin \& J. Sallabank, Endangered Languages: Beliefs and Ideologies in Language Documentation and Revitalization, Oxford: Oxford University Press,125-148.

DORIAN, N. (1981) Language Death: The Life Cycle of a Scottish Gaelic Dialect, Philadelphia: University of Pennsylvania Press.

FISHMAN, J. (1969) Language Loyalty in the United States, The Hague: Mouton.

GAL, S. (1979) Language Shift: Social Determinants of Linguistics Change in Bilingual Austria, New York: Academic Press.

HAUGEN, E. (1969) The Norwegian language in America: A Study in Bilingual Behaviour, Bloomington: Indiana University Press.

HOLMES, J. (1994) An Introduction to Sociolinguistics, London: Longman.

KLoss, H. (1984) “Umrises eines Forschungsprogrammes zum Thema 'Sprachentod'”, International Journal of the Sociology of Language, 45, 65-76.

KRAUSS, M. (1992) “The World's Languages in Crises”, Language, 68 (1), 1-42.

lambert, W. E., hodgson, R. C., gardner, R. C., \& fillenbaum, S. (lambert, W. E., hodgson, R. C., GARDNER, R. C., \& FILLENBAUM, S. (1960) "Evaluational reactions to spoken languages", The Journal of Abnormal and Social Psychology, 60(1), 44-51. $<$ https://doi.org/10.1037/h0044430>.

Le PAge, R. \& A. Tabouret-Keller (1985) Acts of Identity:Creole-Based Approach to Language and Identity, Cambridge: Cambridge University Press.

MCLEOD, S. A. (2008) Social Identity Theory <www.simplypsychology.org/social-identitytheory.html> [retrieved 26 June 2018] 
MOHAMAD SUBAKIR MOHD, Yasin (1998) Language Allegiance and Language Shift, Bangi: Faculty of Language Studies UKM.

PотоWSKI, K. (2013) Language Maintenance and Shift, Oxford: The Oxford Handbook of Sociolinguistics.

TerRA, D. (1983) "The Effects of Language Planning on Penang Hokkien Kampong: People Separated by a Blade of Grass Could Not Understand Each Other", in P. Gosling \& L. Lim (ed.), The Chinese in Southeast Asia: Identity, Culture and Politics, 2, Singapore: Maruzeh Asia, 126-146. 